\title{
Configurações
}

Revista de sociologia

\section{A importância da educação ambiental no processo de defesa do patrimônio natural e cultural: o caso de Piraí da Serra - Paraná, Brasil}

The importance of environmental education to preserve natural and cultural heritage: the case of Piraí da Serra - Paraná - Brazil

L'importance de l'education a l'environnement dans le processus de defense du patrimoine naturel et culturel: le cas de la montagne Piraí - Paraná - Brésil

Edina Schimanski, Jasmine Cardozo Moreira e Paulo Rogério Moro

\section{OpenEdition}

\section{Edição electrónica}

URL: http://journals.openedition.org/configuracoes/1738

DOI: $10.4000 /$ configuracoes. 1738

ISSN: 2182-7419

\section{Editora}

Centro de Investigação em Ciências Sociais

Edição impressa

Data de publição: 1 Junho 2013

Paginação: 113-127

ISBN: 1646-5075

ISSN: 1646-5075

\section{Refêrencia eletrónica}

Edina Schimanski, Jasmine Cardozo Moreira e Paulo Rogério Moro, « A importância da educação ambiental no processo de defesa do patrimônio natural e cultural: o caso de Piraí da Serra - Paraná Brasil », Configurações [Online], 11 | 2013, posto online no dia 22 setembro 2014, consultado o 19 abril 2019. URL : http://journals.openedition.org/configuracoes/1738; DOI : 10.4000/configuracoes.1738 


\title{
A importância da educação ambiental no processo de defesa do patrimônio natural e cultural: o caso de Piraí da Serra - Paraná, Brasil
}

\author{
The importance of environmental education to preserve natural and cultural \\ heritage: the case of Piraí da Serra - Paraná - Brazil \\ L'importance de l'education a l'environnement dans le processus de defense du \\ patrimoine naturel et culturel: le cas de la montagne Piraí - Paraná - Brésil
}

Edina Schimanski, Jasmine Cardozo Moreira e Paulo Rogério Moro

\section{Introdução}

1 A região de Piraí da Serra é constituída por uma paisagem singular e é considerada uma área prioritária no âmbito da conservação na região dos Campos Gerais no estado do Paraná, Brasil. Apesar de esforços empreendidos no sentido de proteger o patrimônio natural, estudos como a Gestão do patrimônio natural dos Campos Gerais (UEPG, 2003) e Caracterização do patrimônio natural dos Campos Gerais do Paraná (Mello et al., 2004) apontam sucessivos processos de degradação da área. Neste cenário, propostas de educação ambiental de caráter crítico-pedagógico tornam-se necessárias para a preservação do patrimônio natural e cultural da região.

O presente texto reflete sobre a importância do desenvolvimento de propostas de Educação Ambiental nesta região e que tenham em consideração práticas transformadoras em defesa do patrimônio natural e cultural deste território. Os resultados analisados no presente artigo fazem parte de um projeto de educação ambiental que está vinculado a um projeto de maior dimensão denominado "Diagnóstico ambiental de Piraí da Serra visando sustentabilidade regional" da Universidade Estadual de Ponta Grossa - UEPG. 
Este projeto de maior dimensão, coordenado pelo Professor Dr. Mário Sérgio de Melo, foi financiado pela Fundação Araucária (Fundação de Apoio ao Desenvolvimento Científico e Tecnológico do Paraná) e foi desenvolvido entre 2008 e 2010. Contou com uma equipa multidisciplinar composta por dezesseis professores pesquisadores de diferentes áreas de atuação (e.g., agricultura sustentável, arqueologia, botânica, ciências sociais, ecologia da paisagem, economia, educação ambiental, geologia regional, geologia sedimentar, geomorfologia e sedimentologia, geoprocessamento, história, petrografia, turismo ecológico e zoologia) e de várias universidades brasileiras. Além das várias universidades, também o Museu Paranaense foi uma das instituições envolvidas no projeto.

O resultado do trabalho desenvolvido pela equipa de Educação Ambiental apresenta na primeira parte do texto uma breve discussão sobre a educação ambiental como instrumento pedagógico de defesa do patrimônio natural e cultural. Serão aqui apresentadas duas vertentes principais relacionadas com os conceitos paradigmáticos da educação ambiental: a vertente conservadora e a vertente crítico-emancipatória. É enfatizada a vertente crítica como opção metodológica imperativa na análise das questões ambientais, sobretudo nas que estão relacionadas com o objeto de pesquisa do presente trabalho: a defesa do patrimônio natural e cultural de Piraí da Serra. A seguir é feita a caracterização da região de Piraí da Serra e a sua relação com a necessidade de uma educação ambiental crítica. Serão mostrados, portanto, o ponto de partida da ação e a problemática de intervenção, bem como a importância de estratégias pedagógicas que levem em consideração a realidade local e ainda o envolvimento da população, sobretudo a relacionada com a esfera educacional, a saber, as escolas da região. Na terceira parte são abordadas as diferentes metodologias de ação que foram desenvolvidas pela equipa e que estão relacionadas com a prática de educação ambiental feitas na comunidade, apresentando os seus avanços e as suas limitações. Após analisados os resultados obtidos pelo grupo de trabalho, apresenta-se a proposta de desenvolvimento de práticas ambientais críticas e emancipatórias.

\section{Educação ambiental e defesa do patrimônio natural e cultural como espaço social}

5 Nas últimas décadas vários autores (e.g., Sauvé, 1997; Loureiro, 2005) têm demonstrado uma crescente preocupação em analisar a trajetória teórico-metodológica da educação ambiental na busca de uma re-significação prático-conceitual para o tema. Depois de um período de emergência e institucionalização, a educação ambiental diversificou-se por um vasto campo teórico, com diferentes significados e fundamentações filosóficas. De fato, a preocupação constante em definir e encaminhar não somente as ações práticas, mas também a pesquisa em educação ambiental tem levado a uma verdadeira "guerra paradigmática" (Gaudiano, 2000), na qual a emergência de novas tendências tem diversificado os processos educativos na área ambiental.

6 Na verdade, a caracterização da prática pedagógica em educação ambiental não está dissociada das orientações filosófi cas que englobam uma discussão sobre os diferentes paradigmas teórico-metodológicos que compõem a esfera de interpretação do ser humano e da sua relação com o meio ambiente. Assim, pode-se dizer que, se estas orientações por si só são suficientemente complexas, mais complexas se tornam quando 
atreladas aos modelos teóricos de interpretação da realidade, os quais têm influenciado as propostas de educação ambiental.

7 Historicamente a educação ambiental tem sido orientada por diferentes paradigmas que norteiam diretamente a sua dimensão prática. Se por um lado isto é positivo, pois instiga o debate em relação ao tema, por outro, pode gerar uma perda de densidade e uma lacuna na compreensão da mesma. Não é nosso objetivo fazer uma discussão epistemológica sobre a validade (ou não) dos diversos paradigmas que têm influenciado a educação ambiental. Deter-nosemos aqui a apresentar alguns fundamentos teóricos e metodológicos e a sua influência no cotidiano da prática dos educadores ambientais. Para tanto, é preciso, primeiro, descodificar o conceito de "paradigma".

Um paradigma pode ser entendido como sendo uma visão do mundo orientada por uma ideologia. Para Capra (apud Fien, 1993), paradigma representa uma constelação de conceitos, valores e percepções comungados por uma comunidade científica. Tais conceitos formam um modo particular e específico de apreender uma dada realidade concreta. De maneira similar, Carr e Kemmis (2002) argumentam que o surgimento de um paradigma acontece quando há a necessidade da elaboração de um corpo teórico de conhecimentos que explique um aspecto específico de um determinado problema. Assim, de acordo com estes autores, um paradigma concentra uma estrutura conceptual singular através da qual a comunidade de pesquisadores opera e através da qual é gerada uma interpretação da realidade. É importante salientar que esta interpretação da realidade (por exemplo: social, política, educacional, ambiental) é que determina o modo como os sujeitos pensam, agem e explicam o mundo. Deste modo, as explicações dos fenômenos ambientais estão fundamentadas numa leitura paradigmática e, por consequência, ideológica desta realidade específica. Apresentaremos a seguir duas vertentes paradigmáticas principais relacionadas com a educação ambiental: a vertente comportamentalista e a vertente emancipatória.

\subsection{Das práticas conservadoras e comportamentalistas à necessidade de uma educação ambiental crítica}

9 Loureiro (2005) aponta que, a partir dos anos setenta do século XX, identificam-se as primeiras experiências denominadas de educação ambiental no Brasil. De acordo com o autor, desde aquela década duas grandes vertentes ideológicas têm influenciado a formulação de paradigmas teóricos na educação ambiental: a vertente conservadora ou comportamentalista e a vertente transformadora ou crítico-emancipatória.

10 A primeira concepção - vertente conservadora -, que dá origem às primeiras práticas da educação ambiental na década de setenta, está diretamente ligada a uma compreensão da educação e da sociedade a partir da influência de matrizes teóricas que enfatizavam o pragmatismo e a adaptação do ser humano ao meio ambiente. Deste modo, o positivismo, a teoria geral dos sistemas, a cibernética, entre outras concepções, influenciaram a construção do chamado paradigma conservador.

11 No final dos anos setenta e início dos anos oitenta, a vertente transformadora começa a emergir no seio das práticas ambientalistas. Esta corrente, fundamentada na concepção do materialismo histórico-dialético (por exemplo, marxismo, escola de Frankfurt), considera a educação como elemento-chave para a compreensão dos problemas ambientais a partir de uma perspectiva crítica e emancipatória onde prevalece a noção de 
justiça social e de cidadania ecológica. Neste contexto, a educação é política e o educando não é um mero receptor do conhecimento, mas um agente político capaz de modificar a sua realidade (Freire, 1988).

12 Não pretendemos neste artigo limitar-nos à compreensão do mundo de forma unilateral e a partir disto entendermos as concepções ambientalistas como se estas pudessem ser pura e simplesmente reduzidas e acopladas em "caixas bipolares", nas quais a educação ambiental estaria comprimida ou dentro de uma conotação tradicionalista ou dentro de uma matriz crítica (Schimanski, 2005). Se assim o fosse, estaríamos restringindo a produção do conhecimento e o agir dos sujeitos a uma dimensão reducionista, sem considerar o próprio movimento dialético da realidade.

13 Contrariamente, é precisamente a partir de uma perspectiva de totalidade, onde as questões ambientais emergem como expressões de múltiplas determinações (históricas, sociais e políticas), que a educação ambiental deve ser entendida. É a partir desta perspectiva crítica que pretendemos apontar alguns elementos sobre a educação ambiental e a defesa do patrimônio natural e cultural, como se verá a seguir.

\subsection{0 patrimônio natural e social como ambiente social e a prática da educação ambiental crítica}

14 Popularmente, a ideia de patrimônio tem sido apontada por organismos nacionais e internacionais como algo pertencente ao mundo, ou seja, como um legado. Da mesma forma, o conceito de patrimônio natural [e cultural] é apresentado como 'herança da humanidade' (ver, por exemplo, UNESCO, 2005). Neste sentido, tanto o patrimônio natural quanto o cultural são reconhecidos como elementos imprescindíveis de uma mesma configuração, a qual é estabelecida entre ser humano e natureza, a partir de uma perspectiva de praxis. A praxis é aqui entendida como expressão das liberdades humanas na ação concreta cotidiana: ação-reflexão-ação. Sendo assim, é anunciada permanentemente a necessidade da responsabilidade ambiental em relação ao patrimônio mundial (UNESCO, 2005: 17).

15 Verificamos que a conservação do patrimônio natural e cultural emerge como elemento sine qua non em processos que envolvem o modelo atual de desenvolvimento da sociedade capitalista, sobretudo na pressuposição daquilo que se pretende como desenvolvimento sustentável. Autores como Ghimiri e Pimbert (2000: 5) apontam que as áreas protegidas são ambientes naturais na medida em que possuem um ecossistema em permanente mudança, mas devem ser entendidas, também, no seu contexto social e cultural, pois são espaços sociais. Fica evidente, na concepção dos autores, que há uma estreita relação entre ser humano e natureza, na medida em que qualquer modificação nos ecossistemas tem de levar em consideração o papel específico desempenhado pelos seres humanos - os quais são, acima de tudo, uma das espécies que habitam o ecossistema (ibidem).

16 Qualquer modificação nas áreas de proteção, ou naquilo que se configura como patrimônio quer natural quer cultural, deve sempre ter a comunidade envolvida no processo. A educação ambiental crítica e transformadora da realidade tem um papel fundamental a partir do envolvimento da comunidade local no estudo das questões ambientais.

17 A UNESCO em 2004, no documento intitulado "Plano Internacional de Implementação para a Década da Educação para o Desenvolvimento Sustentável das Nações Unidas 
(2005-2014)", diz que o "desenvolvimento sustentável engloba educação ambiental, colocando-a no contexto mais amplo dos fatores socioculturais e questões sociopolíticas de igualdade, pobreza, democracia e qualidade de vida" (UNESCO, 2005: 46). Então, pensar uma educação ambiental fundamentada em valores sociais mais amplos, que entenda o ser humano como um elemento essencial no processo de construção, daquilo que se quer por patrimônio natural e cultural, é pensar em estratégias de concretização da autonomia e liberdades humanas na sociedade. Isto significa pensar, portanto, o ser humano a partir de uma perspectiva praxiológica.

\section{Piraí da Serra e educação ambiental}

O desenvolvimento de uma proposta pedagógica que considerasse a realidade local e que, sobretudo, levasse em conta o trabalho já existente sobre a temática era um dos objetivos do projeto. A área de estudo encerra quatro municípios, sendo eles: Castro, Piraí do Sul, Tibagi e Ventania. Não obstante, por uma questão estratégica, a equipa da educação ambiental delimitou a área de pesquisa ao município de Piraí do Sul, cuja área urbana encontra-se mais próxima da região de Piraí da Serra.

A escolha deste município para realização da pesquisa foi no sentido de facilitar o acesso dos pesquisadores e dos atores sociais envolvidos no locus e, também, por ser um município que no decorrer da pesquisa se tornou sede das atividades desenvolvidas por todos os envolvidos no projeto. Segundo o censo demográfico de 2010 do Instituto Brasileiro de Geografia e Estatística (IBGE), o município tinha uma população total de 23 424 habitantes, sendo 16102 na área urbana (68,7\%) e 7322 na área rural (31,3\%).

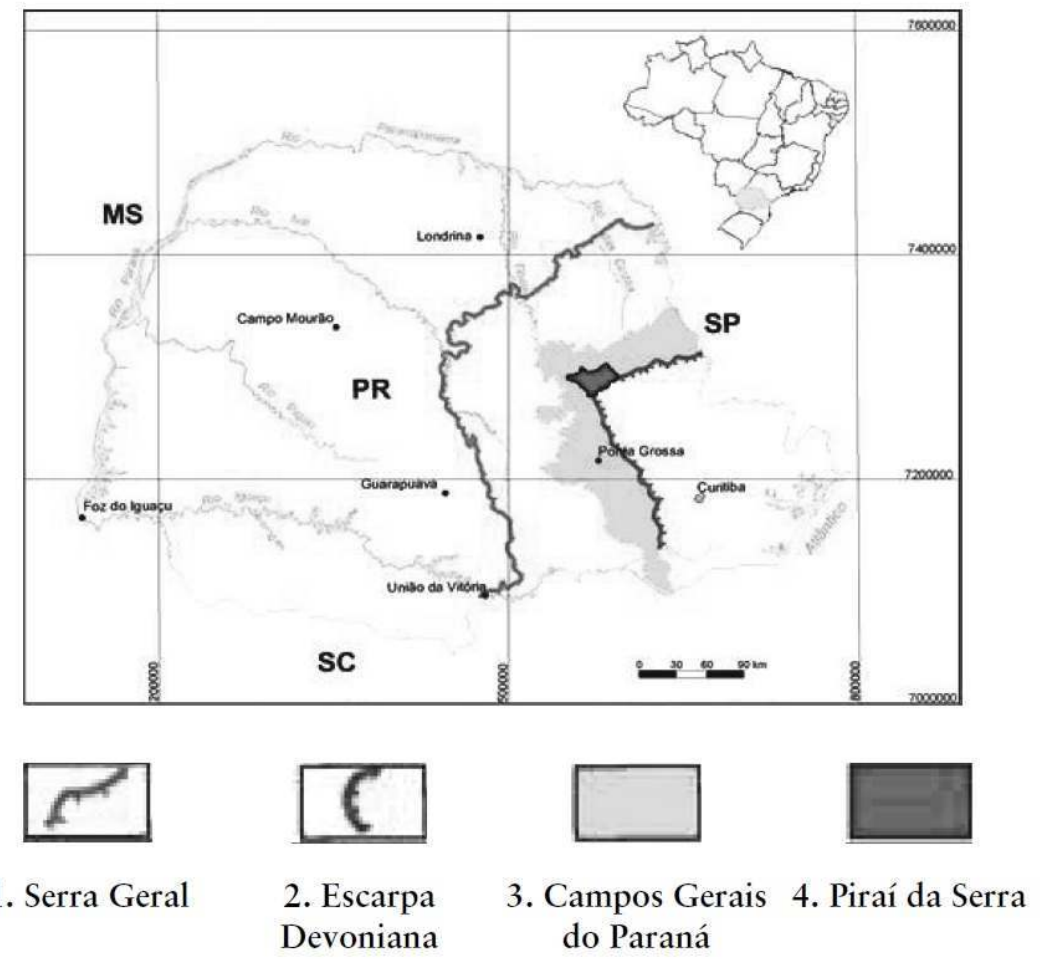

Figura 1. Localização de Piraí da Serra Fonte: Melo (2008) 

seriam processadas, pois uma das premissas do projeto era que seria imprescindível a participação da comunidade nas ações. Ficou estabelecido que as ações não fossem realizadas num formato acrítico e pouco participativo por parte da comunidade. Contrariamente, a ideia de se trabalhar a partir de uma proposta de horizontalidade entre pesquisadores e população permeava o trabalho de campo. Para isto foram escolhidos três sítios sócio-ambientais da comunidade diferentes entre si para participarem do projeto, os quais serão descritos a seguir.

\subsection{A participação dos atores nos sítios sócio-ambientais}

No início do projeto foram realizadas diversas reuniões da equipa de coordenação geral do mesmo com as lideranças políticas do município (prefeito, secretários municipais, lideranças religiosas, proprietários de terra, membros da população) para divulgação do projeto. Após um inventário preliminar na comunidade, pensou-se se haveria possibilidade de se trabalhar com três diferentes tipos de atores e suas respectivas instituições: docentes das escolas municipais e estaduais, lideranças comunitárias ligadas à Igreja (católica e evangélica) e lideranças comunitárias vinculadas à associação dos moradores do município.

A escolha das escolas foi fundamentada na hipótese de que estas estariam trabalhando com a Educação Ambiental conforme estipulado nos temas transversais dos Parâmetros Curriculares Nacionais (Brasil, 1997). A intenção de também trabalhar com as lideranças religiosas foi proposta pela equipa, considerando o interesse da Igreja, sobretudo da católica, na temática do meio ambiente, em virtude de que nos anos anteriores o tema da Campanha da Fraternidade referia-se à temática ambiental, mais especificamente à Amazônia. Quanto à escolha dos terceiros atores - lideranças comunitárias -, esta se deu devido à forte possibilidade de o projeto ter um cunho popular a partir da chamada educação ambiental informal ou não bancária.

Entretanto, à medida que os contatos com os atores sociais foram se realizando, foi se restringindo o número de participantes no projeto de educação ambiental. Primeiro porque não havia na comunidade uma associação de moradores capaz de agrupar pessoas e promover práticas comunitárias, e segundo porque a participação das lideranças religiosas diluiu-se no decorrer do processo. Neste sentido, as escolas foram os agentes sócio-ambientais com os quais se pôde desenvolver um trabalho mais apurado.

\subsection{Metodologia}

Uma vez definidos os atores sociais pela equipa, foi realizada a coleta de dados junto aos professores coordenadores pedagógicos das escolas, através de um questionário semiestruturado contendo seis questões abertas, com o objetivo de conhecer e mapear as práticas pedagógicas da escola relacionadas com a educação ambiental e o patrimônio 
ambiental e natural da região. Num segundo momento foi desenvolvida uma oficina com os professores tendo como temática o Patrimônio Natural e Cultural da região de Piraí da Serra, com o objetivo de apresentar e discutir formas de intervenção na área através da educação ambiental. Outra atividade desenvolvida foi uma saída de campo para estudos na região de Piraí da Serra com os participantes da oficina, com o objetivo de mostrar a área de estudos. E por último foi desenvolvido e entregue nas escolas um material didático de apoio aos professores para o desenvolvimento de atividades com os alunos em sala de aula. Este material será apresentado mais para frente.

\subsection{A prática pedagógica nas escolas} comunidade, e os questionários foram aplicados nas sete escolas existentes na área urbana do município de Piraí do Sul. Foram quatro escolas municipais de Educação Infantil e Ensino Fundamental dos 1. e 2. ciclos, duas escolas estaduais de Ensino Fundamental e Ensino Médio e uma escola privada de Ensino Fundamental e Médio. Os investigadores realizaram contato direto com as coordenações pedagógicas das escolas, e as informações foram obtidas in loco em fevereiro de 2008.

As respostas obtidas através do questionário foram analisadas pela equipa e separadas em três categorias. Na primeira aparecem os problemas ambientais existentes na região; na segunda, o reflexo dos problemas ambientais na vida dos alunos; e na terceira, os projetos de educação ambiental que são desenvolvidos na escola. A equipa optou por manter as respostas que aparecem nos gráficos das fi guras 2, 3 e 4 da mesma forma que foram escritas pelas coordenações entrevistadas.

Em relação aos problemas ambientais existentes na região, o acúmulo de lixo foi apresentado pelas escolas como sendo o maior problema, seguindo-se a existência de terrenos baldios e a poluição do ar (Figura 2).

Embora as professoras coordenadoras pedagógicas das escolas apontassem esses problemas ambientais experimentados pela população, poucas reportaram ações ambientais específicas em relação à vida sócio-ambiental dos discentes e da comunidade 
onde vivem. Uma das entrevistadas citou a organização de uma manifestação com pais e alunos em prol das melhorias das condições ambientais do município.

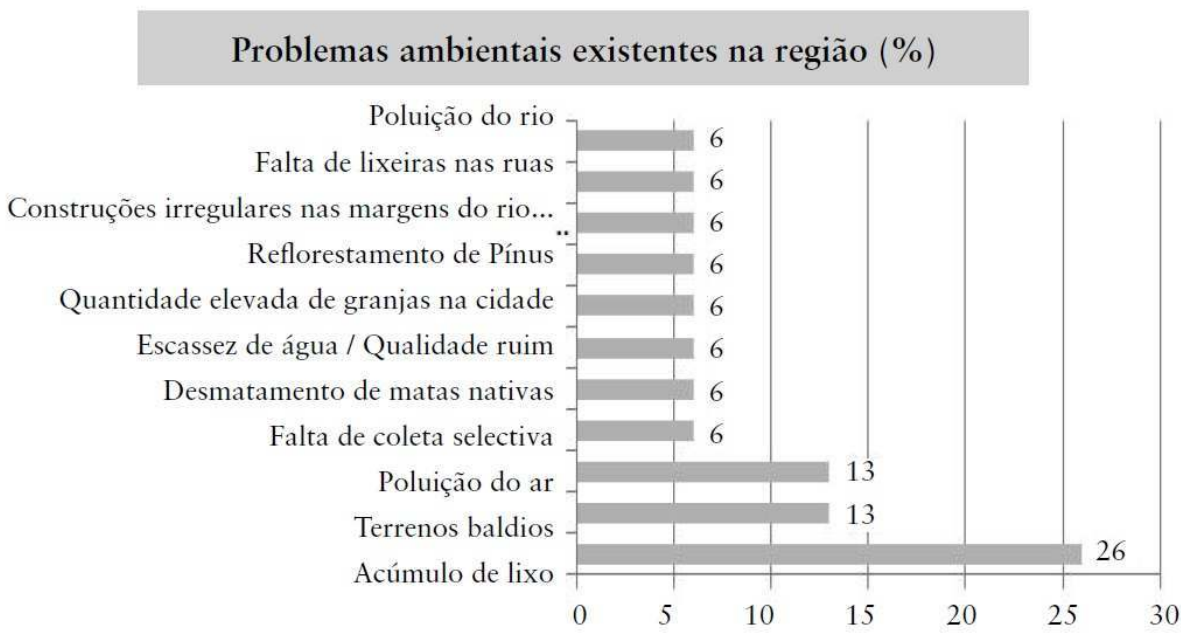

Figura 2. Problemas ambientais existentes na região de Piraí da Serra - 2008

Fonte: autoria própria

A Figura 3 aponta os reflexos dos problemas ambientais na vida dos alunos que foram citados no questionário investigativo. Quase um terço dos investigados (32\%) respondeu desconhecer os reflexos dos problemas ambientais na vida dos alunos. Duas respostas falam de doenças: uma delas cita doenças respiratórias, mas não diz a causa; a outra resposta menciona doenças em geral e também não especifica qual a doença.

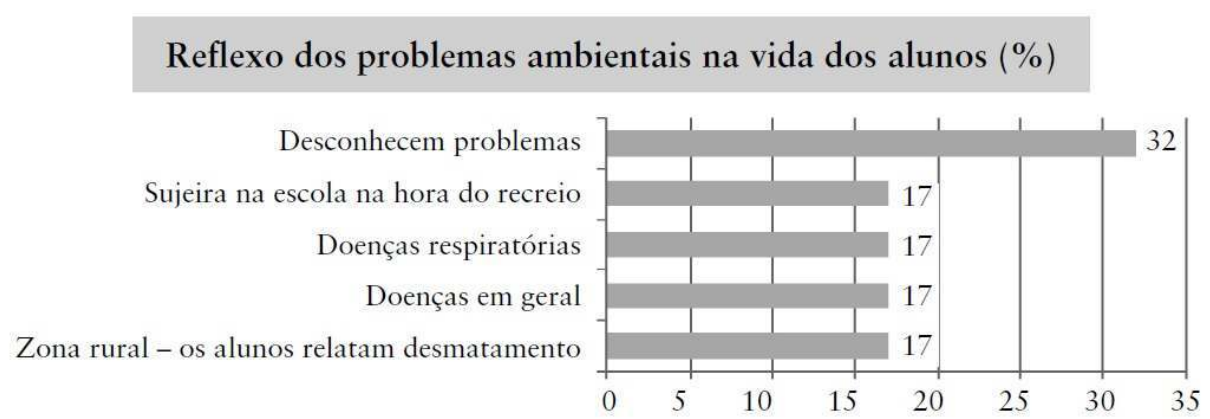

Figura 3. Problemas ambientais existentes na região de Piraí da Serra - 2008

Fonte: autoria própria

\section{Projetos de educação ambiental desenvolvidos na escola (\%)}

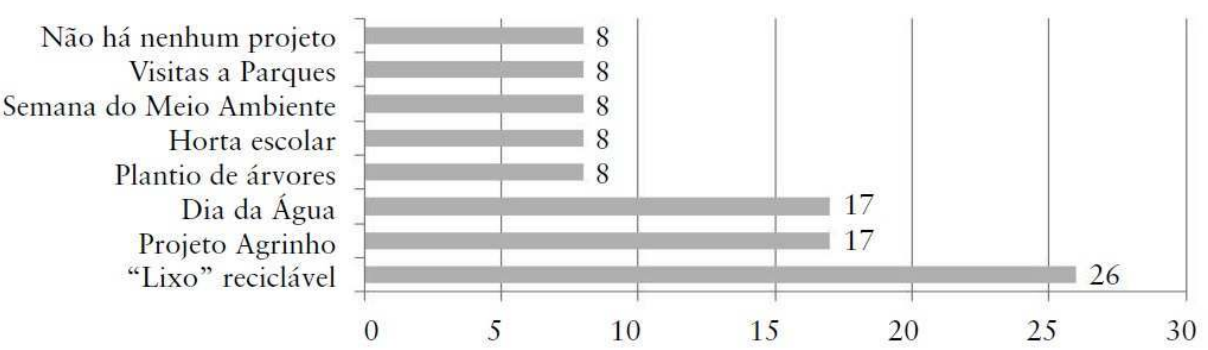

Figura 4. Projetos de Educação Ambiental desenvolvidos nas Escolas - 2008

Fonte: autoria própria 
31 Em geral, embora sentíssemos boa vontade por parte das escolas em realizar um trabalho mais efetivo, as atividades referiam-se a ações reservadas ao interior da mesma e com cunho pontual, como por exemplo, "Dia da Árvore" ou "Dia da Água", entre outras datas comemorativas relacionadas com o meio ambiente. Outras atividades como o Projeto Agrinho (proposto pela Federação da Agricultura do Estado do Paraná (FAEP) para as escolas rurais desde 1995) e trata das questões ambientais relativas ao uso de agrotóxicos. Tais atividades, embora importantes, podem se tornar no cotidiano um pouco questionadoras da realidade social. Corre-se, assim, o risco de haver uma baixa problematização da realidade e pouca evidência em processos históricos no que concerne aos aspectos relacionados com a defesa do patrimônio natural e cultural da região (Figura 4).

Em relação ao patrimônio natural e cultural da região, apenas uma escola, através de uma de suas professoras de História, realizou um trabalho direto com os seus alunos nos sítios arqueológicos que foram encontrados no município. A maior parte das escolas inventariadas, através de seu corpo docente e discente, desconhece o conjunto que representa o patrimônio natural e arqueológico que compõe o cenário de Piraí da Serra e, por consequência, não desenvolve atividades relativas a eles com os seus alunos e alunas.

Em certa medida, o fato de as escolas não conhecerem o patrimônio da região não causou à equipa de educação ambiental estranheza, pois, como aponta McLaren (1995) quando este discute a imposição de culturas externas e predatórias na escola em oposição ao conhecimento e valorização da cultura local, nem sempre a nossa cultura tende a valorizar aquilo que é próprio da região e, sim, aquilo que vem de fora.

Entende-se, portanto, que as escolas são elementos sine qua non no processo de desenvolvimento de uma cultura que não seja alienada e muito menos predatória do local. Como dizem Trajber e Sato (2010),

numa sociedade que se caracteriza pela circulação de tantas identidades diversidades e, especialmente, no cenário dos espaços educadores sustentáveis, pensar a educação é pensá-la diferente" (2010: 71). Também concordamos com as pesquisadoras quando dizem que a escola "deve incitar não apenas responsabilidades ecológicas, mas convidar para repensarmos nossas próprias vidas e o modelo de sociedade", e nos indicam ser isso possível, para "quem acredita que a chamada educação ambiental não é mero pretexto à coleta seletiva de lixo, mas um convite à ressignificação de nossos modos de vida. (Trajber e Sato, 2010: 71)

Se por um lado podemos descrever as práticas de educação ambiental realizadas pelas escolas como sendo singulares e pontuais, por outro lado podemos mencionar a disposição e boa vontade demonstrada pelo corpo docente em participar do projeto sobre o patrimônio natural e cultural de Piraí da Serra.

\section{Oficina temática de sensibilização para intervenção na área}

Uma vez conhecida a realidade das práticas de educação ambiental desenvolvidas nas escolas, partiu-se para a reflexão com os sujeitos envolvidos no processo, ou seja, os professores das escolas, sobre a possibilidade de alargar algumas ações, as quais poderiam contribuir para a divulgação e desenvolvimento de estratégias capazes de fortalecer as escolas para atuarem na defesa do patrimônio natural e cultural da região de Piraí da Serra. 

localidade, o que poderia facilitar o desenvolvimento de práticas pedagógicas ambientais nas escolas fundamentadas numa perspectiva crítica de se entender o meio ambiente nos seus aspectos mais gerais e singulares. instigar o debate e o diálogo entre ciências e cultura popular, redefinindo objetos de pesquisa e ação por parte dos pesquisadores envolvidos no projeto e do grupo de professoras.

\subsection{Proposta lúdico-crítica de Educação Ambiental - Jogo da Memória}

45 Uma atividade proposta pela equipa de educação ambiental foi a confecção de materiais pedagógicos para uso das escolas e também da comunidade. Esta atividade foi considerada 
como uma via para introduzir determinados conceitos e significados relacionados com o patrimônio, que poderão ser trabalhados pelos professores das escolas com o auxílio dos meios interpretativos. A criação de uma atividade pedagógica conhecida popularmente como Jogo da Memória, contendo fotos e informações relativas ao Patrimônio Natural e Cultural dos Campos Gerais, foi apresentada pela equipa. Esta é uma das atividades interpretativas propostas como meio de educação ambiental, também pelo fato de boa parte da comunidade local e regional não conhecer o próprio patrimônio natural e de ser uma atividade que estimula a memória e é fácil de manipular ${ }^{1}$.

No caso das crianças, pode auxiliar na sua alfabetização, uma vez que a leitura do título das cartas pode ser incentivada.

O objetivo é fazer com que os participantes do jogo conheçam com maior abrangência a biodiversidade e geodiversidade da região e para isso todas as

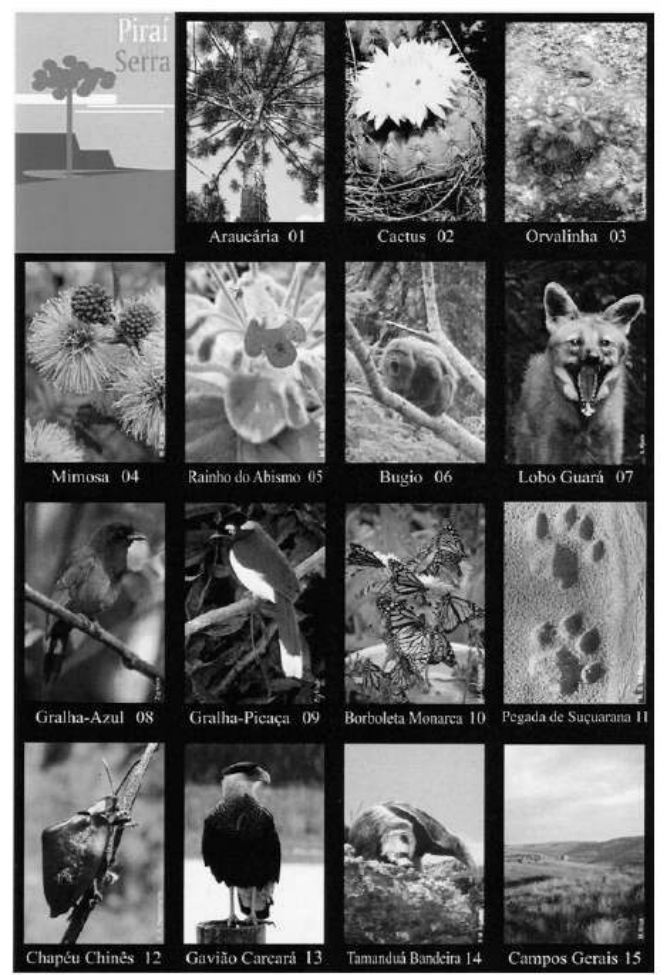

FIgURA 5. JOgO DA MEMÓRIA

FONTE: MOREIRA (2008)

escolas deverão contar com alguns exemplares do mesmo. Na elaboração dos 25 pares de cartas do Jogo da Memória, foram utilizadas fotos relacionadas com o patrimônio natural e cultural num dos lados e no verso de todas as figuras está o logótipo ${ }^{2}$ utilizado no projeto. A Figura 6 apresenta quinze exemplos com fotografias que foram utilizadas no Jogo da Memória.

Além das cartas, foi elaborado um manual para acompanhar a atividade. Tal livreto possui informações sobre o que é o projeto, instruções gerais, um mapa de localização de Piraí da Serra e dados básicos a respeito de cada uma das cartas. A sugestão é utilizar o manual lendo o respectivo texto quando o participante acerta os pares. O Jogo da Memória é um recurso de apoio a atividades de educação para a sustentabilidade (educação ambiental), que procura estimular o reconhecimento e valorização de riquezas ambientais e culturais de Piraí da Serra, incorporando-as na identidade regional. 
50 Além disso, esta ferramenta lúdica pode ser utilizada por outros municípios que queiram valorizar e divulgar ainda mais o seu patrimônio, e é importante que a sua utilização não se restrinja às escolas e atinja um público diversificado, incluindo creches, centros de inclusão, associações de deficientes físicos, turistas, entre outros.

\section{Considerações finais}

51 Uma das ideias centrais da proposta de desenvolvimento de uma educação ambiental crítica é a busca de ruptura e transformação de práticas sociais que não levem em conta valores éticos e sociais relacionados com a natureza e a defesa do patrimônio natural e cultural de uma dada região. Piraí da Serra é um dos poucos espaços que ainda apresenta área preservada. Entretanto, com o desenvolvimento crescente de culturas exóticas na região (e.g., o pinus), existe uma tendência para que o local seja infestado por inteiro em poucos anos. A prática de uma educação ambiental crítica deve estar alicerçada em valores éticos e sociais comprometidos com a defesa deste patrimônio natural local e com sua população.

52 Nas atividades realizadas com as escolas observamos um interesse grande das mesmas em fazer parte de um movimento de defesa do patrimônio local. Entretanto, apesar da boa vontade das escolas, obstáculos podem ser citados no processo, os quais dificultaram a realização das atividades de educação ambiental.

53 Uma dificuldade foi o fato de que as escolas não possuem acesso à internet, o que, sem dúvida, inviabiliza a participação das mesmas nas redes de educação ambiental. As redes de educação ambiental são uma possibilidade importante de acesso à informação, diálogo e produção de saberes que podem contribuir eficazmente na defesa do patrimônio natural e cultural da região.

Apesar das dificuldades apresentadas, a possibilidade de participar do projeto e discutir com as escolas permitiu um maior conhecimento sobre a região. Neste sentido, percebe-se que as atividades desenvolvidas permitiram uma aproximação mais densa com a realidade da região. Isto pode, apesar dos obstáculos, germinar um processo de politização da problemática ambiental experimentada em Piraí da Serra na sua totalidade e complexidade.

\section{BIBLIOGRAFIA}

BRASIL. Secretaria de Educação Fundamental (1998), Parâmetros curriculares nacionais: terceiro e quarto ciclo: apresentação dos temas transversais. Brasília, DF: MEC/SEF.

CARR, W. \& KEMMIS, S. (2002), Becoming Critical. Education, knowledge and action research, Londres: Routledge Farmer.

FIEN, J. (1993), Education for the Environment. Critical curriculum theorising and Environmental Education. Australia: Deakin University. 
FREIRE, P. (1988), Pedagogia do oprimido. 18. e ed. Rio de Janeiro: Paz \& Terra.

GAUDIANO, E. (2002), Environmental Education. Disponível em: www.vusst.hr/ENCYCLOPAEDIA/ environmental_education.htm [Acesso em 01.02.2005].

GHIMIRI, K. \& PIMBERT, M. (2000), "Social change and conservation: an overview of issues and concepts", in K. Ghimiri \& M. Pimbert, Social Change and Conservation, Londres: Earthscan Publications.

MOREIRA, J. C. (2008), Patrimônio Geológico em Unidades de Conservação: Atividades interpretativas, educativas e geoturísticas. Tese de Doutorado. Programa de Pós Graduação em Geografia da Universidade Federal de Santa Catarina: Florianópolis.

LOUREIRO, C. F. B. (2005), Complexidade e dialética: contribuições à práxis política e emancipatória em educação ambiental. Educ. Soc., dez. 2005, vol.26, no. 93: 1473-1494.

LOUREIRO, C. F. B. (2004), Trajetória e fundamentos da Educação Ambiental. SP: Cortez.

MCLAREN, P (1995), Critical Pedagogy and Predatory Culture. Oppositional politics in a postmodern era, Londres: Routledge.

MELO, Mário Sérgio de; MORO, Rosemeri Segecin; GUIMARÃES, Gilson Burigo (Orgs.) (2007), Patrimônio natural dos Campos Gerais do Paraná. Ponta Grossa: Editora da UEPG. v. 1.

SCHIMANSKI, E. (2005), Developing Environmental Education in Brazilian Primary Schools Focused on Emancipatory Actions and Ecological Citizenship: an action research approach. PhD Thesis. Institute of Education, University of London.

SCHIMANSKI, E. (2005) "Critical environmental education towards emancipatory action: an overview”, PhD Essays: Literature Surveys and Other Anxieties. 1st ed. Londres: Institute of Education, University of London.

SAUVÉ, L. (1997), “Educação Ambiental e Desenvolvimento Sustentável: uma análise complexa”, Revista de Educação Pública, vol. 10, jul./dez.

TRAJBER, R. \& SATO M. (2010), “Escolas Sustentáveis: Incubadoras de Transformações nas Comunidades", Revista do PPGEA/FURG-RS.

UNESCO (2005), World Heritage at the Vth IUCN. World Parks Congress - South Africa (Sep. 2003) Published by UNESCO - Paris.

UNESCO (2005), Década da Educação das Nações Unidas para um Desenvolvimento Sustentável, 2005-2014: documento final do esquema internacional de implementação. Brasília: UNESCO.

\section{NOTAS}

1. Cada participante na sua vez vira duas cartas e deixa que todos as vejam. Caso sejam iguais, participante deve recolher esse par. Se forem peças diferentes, estas devem ser viradas novamente, passando a vez ao participante seguinte. Ganha aquele que tiver descoberto mais pares.

2. Logótipo criado pelo designer Élio Chaves. 


\section{RESUMOS}

O presente texto reflete sobre a importância do desenvolvimento de propostas de educação ambiental na região de Piraí da Serra (estado do Paraná-Brasil) que tenham em consideração práticas transformadoras em defesa do patrimônio natural e cultural do território. A região de Piraí da Serra possui uma paisagem singular e é considerada como área prioritária de conservação, nos chamados Campos Gerais. Apesar de esforços empreendidos no sentido de proteger o patrimônio natural, estudos in loco apontam sucessivos processos de degradação daquele território. Neste cenário, propostas de educação ambiental de caráter crítico-pedagógico tornam-se imprescindíveis para a preservação do patrimônio natural e cultural da região.

This essay focus on the importance of developing environmental education practices in the region of the Piraí da Serra (Paraná - Brazil) that takes into consideration transformative actions towards the defence of natural and cultural heritage of the area. The region is characterized by a singular landscape and it is considered by people as an important area of conservation in the Campos Gerais. Despite some efforts to protect the local natural heritage some studies have showed a continuous process of degradation. In this scenario, it is fundamental to develop a critical pedagogic process of environmental education in order to preserve and restore natural and cultural heritage of the region.

Ce texte se penche sur l'importance d'élaborer des propositions pour l'éducation environnementale dans la région de la Sierra Pirai (Paraná, Brésil) qui prennent en considération les pratiques transformatrices dans la défense du patrimoine naturel et culturel de la région. La région se compose d'un paysage unique est considérée comme un domaine prioritaire pour la conservation, appelée Campos Gerais. Malgré les efforts pour protéger le patrimoine naturel, des études in situ indiquent processus successifs de la dégradation du territoire. Dans ce scénario, les propositions d'éducation environnementale caractère critique pédagogique devenu indispensable à la préservation du patrimoine naturel et culturel de la région.

\section{ÍNDICE}

Palavras-chave: desenvolvimento sustentável, educação ambiental, patrimônio, sustentabilidade

Mots-clés: développement durable, éducation à l'environnement, patrimoine

Keywords: sustainable development, environmental education, heritage, sustainability

\section{AUTORES}

\section{EDINA SCHIMANSKI}

PhD em Educação - Professora Adjunta da Universidade Estadual de Ponta Grossa -

Departamento de Serviço Social

edinaschi@hotmail.com 


\section{JASMINE CARDOZO MOREIRA}

Doutora - Professora Adjunta da Universidade Estadual de Pont Grossa - Departamento de Turismo

jasmine@uepg.br

\section{PAULO ROGÉRIO MORO}

Mestre em Educação - Professor Assistente da Universidade Estadual de Ponta Grossa Departamento de Métodos e Técnicas de Ensino

paulomoro@uepg.br 